\title{
LXI. Investigation of the transformation of certain elliptic functions
}

\section{Arthur Cayley Esq. B.A. F.C.P.S.}

To cite this article: Arthur Cayley Esq. B.A. F.C.P.S. (1844) LXI. Investigation of the transformation of certain elliptic functions , Philosophical Magazine Series 3, 25:167, 352-354, DOI: $10.1080 / 14786444408645012$

To link to this article: http://dx.doi.org/10.1080/14786444408645012

曲 Published online: 30 Apr 2009.

Submit your article to this journal $[\pi$

Џll Article views: 2

Q View related articles $\asymp$ 
LXI. Investigation of the Transformation of certain Elliptic Functions. By Arthur CaYley, Esq., B.A., F.C.P.S., Fellow of Trinity College, Cambridge.

To the Editors of the Philosophical Magazine and Journal. Gentilemen,

T should be obliged if you would do me the favour of insertI ing the following investigation of the transformation of elliptic functions, which appear to me completely to demonstrate that no limitations are required in Jacobi's conclusions (see Phil. Mag. S. 3, vol. xxii. p. 358; xxiii.p. 89). I should not have resumed the subject had not the method employed seemed to me to possess some independent interest.

\section{I remain,}

Your obedient Servant,

29 York Terrace, October 10, 1844.

A. Cayley.

The function sin $a m u$ ( $\phi u$ for shortness) may be expressed in the form

$$
\left.\begin{array}{rl}
\phi u & =u \Pi\left(1+\frac{u}{2 m \mathrm{~K}+2 m^{\prime} \mathrm{K}^{\prime}}\right) \\
& \div \Pi\left(1+\frac{u}{2 m \mathrm{~K}+\left(2 m^{\prime}+1\right) \mathrm{K}^{\prime}}\right)
\end{array}\right\}, . .
$$

where $m, m^{\prime}$ receive any integer, positive or negative, values whatever, omitting only the combination $m=0, m^{\prime}=0$ in the numerator (Abel, OEuvres, t. I. p. 212, but with modifications to adapt it to Jacobi's notation; also the positive and negative values of $m, m^{\prime}$ are not collected together as in Abel's formulæ). We deduce from this

$$
\left.\begin{array}{rl}
\frac{\Phi(u+\theta)}{\phi \theta} & =\Pi\left(1+\frac{u}{2 m \mathrm{~K}+2 m^{\prime} \mathrm{K}^{\prime} \iota+\theta}\right) \\
+ & \Pi\left(1+\frac{u}{2 m \mathrm{~K}+\left(2 m^{\prime}+1\right) \mathrm{K}^{\prime} \iota+\theta}\right)
\end{array}\right\} . .
$$

Suppose now $\mathrm{K}=a \mathrm{H}+a^{\prime} \mathrm{H}^{\prime}, \mathrm{K}^{\prime} \iota=b \mathrm{H}+b^{\prime} \mathrm{H}^{\prime} \downarrow, a, b, a^{\prime}, b^{\prime}$ integers, and $a b^{\prime}-a^{\prime} b$ a positive number (v). Also let $\omega=f \mathrm{H}+f^{\prime} \mathrm{H}^{\prime} ; f, f^{\prime}$ integers such that $a f^{\prime}-a^{\prime} f, b f^{\prime}-b^{\prime} f$, $v$, have not all three any common factor. Consider the expression

from which

$$
u=\frac{\Phi u \cdot \Phi(u+2 \omega) \ldots \Phi(u+2(\nu-1) \omega) .}{\Phi(2 \omega) \ldots \phi(2(\nu-1) \omega)}, \quad .
$$

$$
\left.\begin{array}{rl}
v= & u \Pi\left(1+\frac{u}{2 m \mathrm{~K}+2 m^{\prime} \mathrm{K}^{\prime} \iota+2 r^{\theta}}\right) \\
& \div \Pi\left(1+\frac{u}{2 m \mathrm{~K}+\left(2 m^{\prime}+1\right) \mathrm{K}^{\prime} \mathbf{1}+2 r^{\theta}}\right)
\end{array}\right\}
$$


where $v$ extends from 0 to $\nu-1$ inclusively, the single combination $m=0, m^{\prime}=0, r=0$ being omitted in the numerator. We may write

$$
m \mathrm{~K}+m^{\prime} \mathrm{K}^{\prime} \iota+r \theta=\mu \mathrm{H}+\mu^{\prime} \mathrm{H}^{\prime} \text {, }
$$

$\mu, \mu^{\prime}$ denoting any integers whatever. Also to given values of $\mu, \mu^{\prime}$ there corresponds only a single system of values of $m, m^{\prime}, \theta$. To prove this we must show that the equations

$$
\begin{aligned}
& m a+m^{\prime} b+r f=\mu, \\
& m a^{\prime}+m^{\prime} b^{\prime}+r f^{\prime}=\mu,
\end{aligned}
$$

can always be satisfied, and satisfied in a single manner only. Observing the value of $y$,

$$
\nu m+r\left(b^{\prime} f-b f^{\prime}\right)=\mu b^{\prime}-\mu^{\prime} b ;
$$

and if $v$ and $b^{\prime} f-b f^{\prime}$ have no common factor, there is a single value of $r$ less than $y$, which gives an integer value for $m$. This being the case, $m^{\prime} b$ and $m^{\prime} b^{\prime}$ are both integers, and therefore, since $b, b^{\prime}$ have no common factor (for such a factor would divide $v$ and $\left.b^{\prime} f-b f^{\prime}\right), m^{\prime}$ is also an integer. If, however, $v$ and $b^{\prime} f-b f^{\prime}$ have a common factor $c$, so that $\nu=a b^{\prime}-a^{\prime} b=c \phi$, $b^{\prime} f-b f^{\prime}=c \phi ;$ then $\left(a f^{\prime}-a^{\prime} f\right) b^{\prime}=c .\left(\phi f^{\prime}-\phi^{\prime} f\right)$, or since no factor of $c$ divides $a f^{\prime}-a^{\prime} f, c$ divides $b^{\prime}$, and consequently $b$. The equation (7.) may therefore be divided by $c$. Hence, putting $\frac{\nu}{c}=\nu_{j}$, we may find a value of $r, r_{1}$ suppose, less than $\nu_{j}$, which makes $m$ an integer; and the general value of $r$ less than $v$ which makes $m$ an integer, is $r=r_{1}+s v_{p}$, where $s$ is a positive integer less than $c$. But $m$ being integral, $b m^{\prime}, b^{\prime} m^{\prime}$, and consequently $c \mathrm{~m}^{\prime}$ are integral; we have also

$$
\nu m^{\prime}+\left(r_{1}+s v_{l}\right) \cdot\left(a f^{\prime}-a^{\prime} f\right)=a \mu^{\prime}-a^{\prime} \mu ;
$$

or dividing by $\nu_{p}$,

$$
\left.c m^{\prime}\right)+s .\left(a f^{\prime}-a^{\prime} f\right)=\mathrm{I}
$$

an integer, where $c$ and $a f^{\prime}-a^{\prime} f$ are prime to each other. Hence there may be found a single value of $s$ less than $c$, giving an integer value for $m^{\prime}$. Hence in every case there is a single system of values of $m, m^{\prime}, r$, corresponding to any assumed integer values whatever of $\mu, \mu^{\prime}$. Hence

$$
\left.\begin{array}{rl}
\mathrm{U}= & u \Pi\left(1+\frac{u}{2 \mu \mathrm{H}+2 \mu^{\prime} \mathrm{H}^{\prime}}\right) \\
& \div \Pi\left(1+\frac{u}{2 \mu \mathrm{H}+\left(2 \mu^{\prime}+1\right) \mathrm{H}^{\prime}}\right)=\Phi_{1} u .
\end{array}\right\} .
$$

$\phi_{1} u$ being a function similar to $\phi u$, or $\sin a m u$, but to a different modulus, viz. such that the complete functions are $\mathrm{H}, \mathrm{H}^{\prime}$ instead of $\mathrm{K}, \mathrm{K}^{\prime}$. We have therefore

Phil. Mag. S. 3. Vol. 25. No. 167. Nov. 1844. 


$$
\phi_{1} u=\frac{\phi u \cdot \Phi(u+2 \omega) \ldots \phi(u+2(\nu-1) \omega)}{\phi 2 \omega \ldots \phi 2(\nu-1) \omega} .
$$

Expressing $\omega$ in terms of $\mathrm{K}, \mathrm{K}^{\prime}$, we have $\nu \mathrm{H}=b^{\prime} \mathrm{K}-a^{\prime} \mathrm{K}^{\prime}$, $-\nu \mathrm{H}^{\prime} b=b \mathrm{~K}-a \mathrm{~K}^{\prime} b$ and $\therefore v \omega=\left(b^{\prime} f-b f^{\prime}\right) \mathrm{K} \rightarrow\left(a^{\prime} f-a f^{\prime}\right) \mathrm{K}^{\prime}{ }^{\prime}$. Let $g, g^{\prime}$ be any two integer numbers having no common factor,

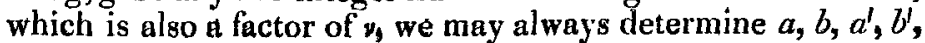
so that $v \omega=g \mathrm{~K}-g^{\prime} \mathbf{K}^{\prime}$. . This will be the case if $g=b^{\prime} f-b f^{\prime}$ $g^{\prime}=a^{\prime} f-a f^{\prime}$. One of the quantities $f, f^{\prime}$ may be assumed equal to 0. Suppose $f^{\prime}=0$, then $g=b^{\prime} f, g^{\prime}=a^{\prime} f$; whence $a g-b g^{\prime}=\nu f$. Let $k$ be the greatest common measure of $g, g^{\prime}$, so that $g=k g, g^{\prime}=k g_{l}^{\prime}$; then, since no factor of $k$ divides $\%$, $k$ must divide $f$, or $f=k f_{1}$, but $g,=b^{\prime} f, g^{\prime},=a f^{\prime}$, and $a^{\prime}, b^{\prime}$ are integers, or $f$ must divide $g, g^{\prime}$; whence $f_{1}=1$, or $f=k$. Also $a g,-b g_{1}^{\prime}=v$, where $g$, and $g^{\prime}$ are prime to each other, so that integer values may always be found for $a$ and $b$; so that in the equation (1.),

$$
\omega=\frac{g \mathbf{K}-g^{\prime} \mathbf{K}^{\prime} \text { ! }}{\nu .} . . . . .
$$

$g, g^{\prime}$ being any integer numbers, such that no common factor of $g, g^{\prime}$ also divides $y$.

The above supposition, $f^{\prime}=0$, is, however, only a particular one, omitting it, the conditions to be satisfied by $a, b, a^{\prime}, b^{\prime}$, may be written under the form

$$
\left.\begin{array}{rl}
a b^{\prime}-a^{\prime} b & =\nu, \\
a g-b g^{\prime} & \equiv 0[\bmod . \nu], \\
a^{\prime} g-b^{\prime} g^{\prime} & \equiv 0[\bmod . \nu],
\end{array}\right\} . . \cdot .
$$

to which we may join the equations before obtained,

$$
\left.\begin{array}{rl}
\nu \mathrm{H} & =b^{\prime} \mathrm{K}-a^{\prime} \mathrm{K}^{\prime}, \\
-\nu \mathrm{H}^{\prime} \iota & =b \mathrm{~K}-a \mathrm{~K}{ }^{\prime},
\end{array}\right\} . . . . .
$$

which contain the theory of the modular equation. This, however, involves some further investigations, which are not sufficiently connected with the present subject to be attempted here.

LXII. On Polarization and Double Refraction. By R. Moon, M.A., Fellore of Queen's College, Cambridge, and of the Cambridge Philosophical Society*.

$\mathrm{N}$ a paper published in this Journal some months agot, $\mathrm{I}$ endeavoured to give a popular explanation of the phrenomena of diffraction, and I attempted to show that those phænomena may be accounted for on the hypothesis, that the waves composing common light consist of recurring cycles of waves, the individuals of each cycle being related in a certain manner to each other, and occurring at regular finite inter-

* Communicated by the Author. + S. 3. vol. xxiv. p. 81 . 